\title{
Using Scrap Tires to Fight Desertification and Ration Water by Value Engineering Approach
}

\author{
F.S. Al-Anzi ${ }^{1}$, M. Sarfraz ${ }^{2}$ and A. Elmi ${ }^{3}$, and A.R. $\mathrm{Khan}^{4}$
}

\begin{abstract}
The Value Methodology (VM), a systematic and structured approach, improves projects, products, and processes. VM is used to analyze design solutions, products and processes. VM helps to achieve balance between required functions, performance, quality, safety, and scope with the cost and other resources necessary to accomplish those requirements. The proper balance results in the maximum value for the project.

In this research project, we use VM to design an alternative solution to problem by analyzing the quality criteria of an existing original design and propose a higher value design alternatives. This study proposes an economical alternative design to well-known technology of Waterboxx kits. The new design makes use of used tires and recycled plastic sheets as raw material. More details about the design approach is addressed in the paper. The controlled testing of the alternative design as well as the filed study show that new proposed design outperformed the original design value as per clients requires.
\end{abstract}

Kuwait is facing environmental challenges. some of which are natural while others are manmade. Responding to these challenges in localized, innovative, effective and economic ways are the encounters that researchers rising to. One of the vital and significant examples of the natural challenges is desertification. Desertification is a type of land degradation in which a relatively dry land region becomes increasingly arid, typically losing its bodies of water as well as vegetation and wildlife. It is caused by a variety of factors, such as climate change and human activities. Desertification is a significant global ecological and environmental problem. Fighting desertification requires huge investment and technological solutions that most of the times are becoming hard to maintain and hence they become not economical and manageable in the long run. This research project focuses in the following directions:

- Getting rid of ever-growing huge tire dumpsters in Kuwait in a safe and environmental friendly manner.

- Finding out an economical alternative to well-known technology of Waterboxx kits.

- Harvesting rain water/mist and managing the most valuable water resources.

- Capacity building in planting shrubs and trees in Kuwait deserts using state of the art techniques.

The project is funded by Kuwait Foundation for Advancement of Science (KFAS), and currently being executed under the supervision of Kuwait University Research Administration. This paper summarizes the progress for the first two years of the project and in

F.S. Al-Anzi ${ }^{1}$ is with Kuwait University, Kuwait.

M. Sarfraz is with Kuwait University, Kuwait.

A. Elmi ${ }^{3}$ is with Kuwait University, Kuwait.

A.R. Khan ${ }^{4}$ is with Kuwait Institute of Scientific Research, Kuwait. which we explain the progress as per the time plan of the three years project duration.

Keywords-Fight Desertification; Ration Water; Waste Recycling; Scrap Tires; Value Engineering Approach

\section{INTRODUCTION}

$\mathrm{K}_{\mathrm{D}}^{\mathrm{L}}$ UWAIT is facing many environmental challenges. Desertification is a type of land degradation in which a relatively dry land region becomes increasingly arid, typically losing its bodies of water as well as vegetation and wildlife [4]. It is caused by a variety of factors, such as climate change and human activities. Desertification is a significant global ecological and environmental problem [4]. Fighting desertification [5], see Figure 1, requires huge investment and technological solutions that most of the times are becoming hard to maintain and hence they become not economical and manageable in the long run. (a)

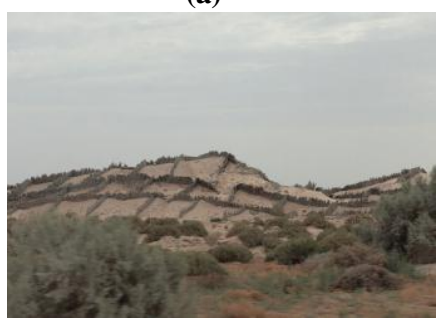

(b)

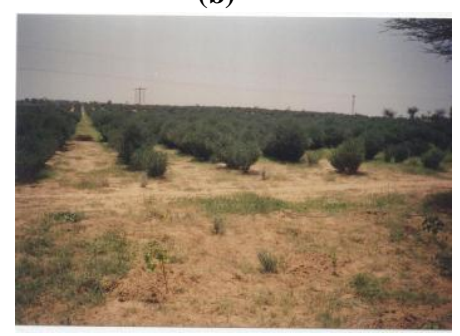

Fig. 1: Fighting desertification: (a) Anti-sand shields in north Sahara, Tunisia, (b) Jojoba plantations, such as those shown, have played a role in combating edge effects of desertification in the Thar Desert, India.

Water scarcity is by far the most serious national issue in the state of Kuwait. Nearly all potable water consumed in Kuwait (close to 95\%) is obtained from seawater through an expensive and environmentally costly desalinization process [10]. Water consumption is expected to increase significantly due to rapid population growth coupled with a rise of standard of living, which will eventually necessitate in the production of large quantities of desalted water with huge amounts of energy input Recently, El Kharraz et al. [11] analyzed the issue of water scarcity and the role of desalinization. They listed some of the important environmental impacts associated with desalination, including entrapment of aquatic creatures in plants intakes, discharge of hot brine and the production of $\mathrm{CO}_{2}$. Consequently, the long term environmental sustainability and 
energy use for sea water desalination may become increasingly questionable. There are some other ideas on agricultural, environmental and hydrological considerations in the current literature. For brevity, the reader is referred to [20-31].

\section{THE IDEA}

The study focuses an economical alternative to well-known technology of Waterboxx kits in Figure 2(a). This is going to be an essential part of this pilot study. An initial and preliminary crude design alternative is proposed as shown in Figure 2(b). It simply consumes used tires and recycled plastic sheets as material. Hence, the study is going to help not just getting rid of ever growing huge tire dumpsters in Kuwait (see Figure 3), but it will also help avoiding hazards like tire fires (see Figure 4) in a safe and environmental friendly manner.

This study proposes an economical alternative to wellknown technology of Waterboxx kits in Figure 4(a). This is going to be an essential part of this pilot study. An initial and preliminary crude design alternative is proposed as shown in Figure 4(b). It simply consumes used tires and recycled plastic sheets as material. More details of the design would be addressed later.

The newly proposed Waterboxx technique using tires would be considered to measure the quality of the methodology. To find out the quality of the method, we will consider multiple farms at different places. In each farm, number tirewaterboxxes would be tested for tree plantations. This setting would allow to obtain a $2 \times 2$ contingency table, as shown in Table I, which contains four values, denoted as TN, FP, FN, and TP, where T, F, N, and P refer to true, false, negative, and positive. In the context of proposed methodology, these notations have the following interpretations:

- TN: represents the number of plants correctly grown to not trees,

- FP: represents the number of plants incorrectly grown to trees,

- FN: represents the number of plants incorrectly grown to not trees,

- TP: refers to the number of plants correctly grown to trees.

To evaluate the plantation performance of the tirewaterboxx technique, we will use the traditional precision and recall evaluation criteria of Olson and Delen [14]. Precision and Recall are defined as follows:

$$
\text { precision }=\frac{T P}{T P+F P} \text { and recall }=\frac{T P}{T P+F N}
$$

FMeasure [15] is a factor that considers both precision and recall and it has a single value that expresses the quality of the classification. It is defined as the harmonic mean of precision and recall and it is formally obtained as follows:

$$
\text { Fmeasure }=\frac{2 \times \text { precision } \times \text { recall }}{\text { precision }+ \text { recall }} .
$$

(a)

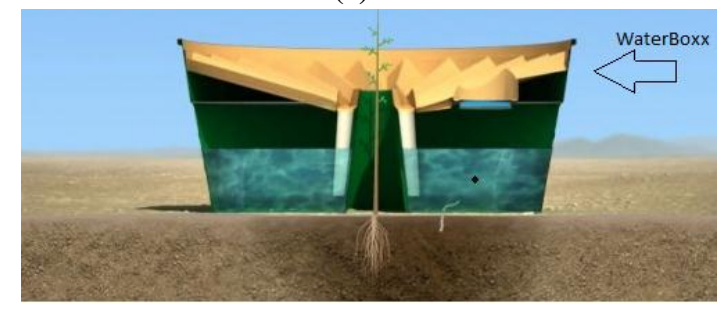

(b)

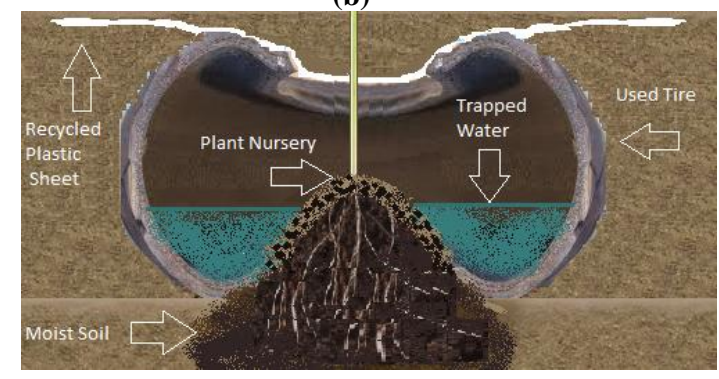

Fig. 2: Waterboxx kit: (a) Original design, (b) Proposed alternative design.

TABLE I CONTINGENCY TABLE

$\begin{array}{cccc} & & \text { Actual Plants planted } \\ & & 0 & 1 \\ \text { Plants } & 0 & \text { TN } & \text { FN } \\ \text { grown to } & & & \\ \text { Trees } & 1 & \text { FP } & \text { TP }\end{array}$

The proposed methodology would be tested on variety of farms for its proper evaluation. It is anticipated, after extensive experimentations, the proposed technique would produce very high quality results.

The Value Methodology (VM) [11-13], a systematic and structured approach, improves projects, products, and processes. VM is used to analyze design solutions, products and processes. VM helps to achieve balance between required functions, performance, quality, safety, and scope with the cost and other resources necessary to accomplish those requirements. The proper balance results in the maximum value for the project. The VM focuses on the optimization of the objective function of :

where:

$$
\text { Value }=\text { Function } / \text { Cost }
$$

- Value is the reliable performance of functions to meet customer needs at the lowest overall cost.

- Function is the natural or characteristic action performed by a product or service.

- Cost is the expenditure necessary to produce a project, service, process, or structure.

The systematic and structural approach comes from the VM job plan. It is a standard job plan that consists of the following six phases:

1. Information Phase: Gather information to better understand the project. 
2. Function Analysis Phase: Analyze the project to understand and clarify the required functions.

3. Creative Phase: Generate ideas on all the possible ways to accomplish the required functions.

4. Evaluation Phase: Synthesize ideas and concepts to select feasible ideas for development into specific value improvement.

5. Development Phase: Select and prepare the "best" alternative(s) for improving value.

6. Presentation Phase: Present the value recommendation to the project stakeholders.

The VM process produces the best results when applied by a multi-disciplinary team with experience and expertise relative to the type of project to be studied. A Certified Value Specialist leads the VM team to ensure proper application of the methodology. Value Specialist has to be certified by the SAVE International® [3] to lead such studies.

VM is embraced by a global spectrum of businesses and industries: building designers and contractors; automobile manufacturers; chemical processors; pharmaceutical companies; etc. Benefits realized by those companies using VM far exceed the investment. Savings in time, cost, and quality contribute to improve a competitive position.

In this research we use VM to design an alternative solution to problem by analyzing the quality criteria of the original design and the proposed alternative. Table II and Figure 3 demonstrate the quality profile of both designs.

\section{EXPERIMENT SETUP}

This project proposes to build a case to utilize a team knowledge in VM to embrace a viable alternative to reuse scrap tires in Kuwait tire dumpster to fight desertification as well as help irrigation water rationing in farms that facilitate wind breaking from native shrubs and trees. The innovative idea is to utilize the used tires from the tire dumpsters as an economical alternative to well-known technology of Waterboxx kits. Waterboxx kits have been proved to help reducing the amount of irrigation used to help plant trees in deserts. The Project will focus on the following three directions:

1. Getting rid of ever growing huge tire dumpsters in Kuwait in a safe and environmental friendly manner.

2. Harvesting rain water and managing the most valuable water resources.

3. Capacity building in planting shrubs and trees in Kuwait deserts using state of the art techniques.

TABLE II

QUALITY PROFILE OF ORIGINAL AND PROPOSED DESIGNS

\begin{tabular}{|cccc|}
\hline No. & Criteria & WaterBoxx & Used Tires \\
\hline 1 & Ease of Assembly & 5 & 10 \\
\hline 2 & Robustness & 4 & 10 \\
\hline 3 & Durability & 6 & 10 \\
\hline 4 & Availability & 5 & 10 \\
\hline 5 & Scalability & 6 & 9 \\
\hline 6 & Reuse & 6 & 9 \\
\hline 7 & Solving Current & 2 & 10 \\
\hline 8 & Learning Curve & 5 & 9 \\
\hline
\end{tabular}

Quality Profile

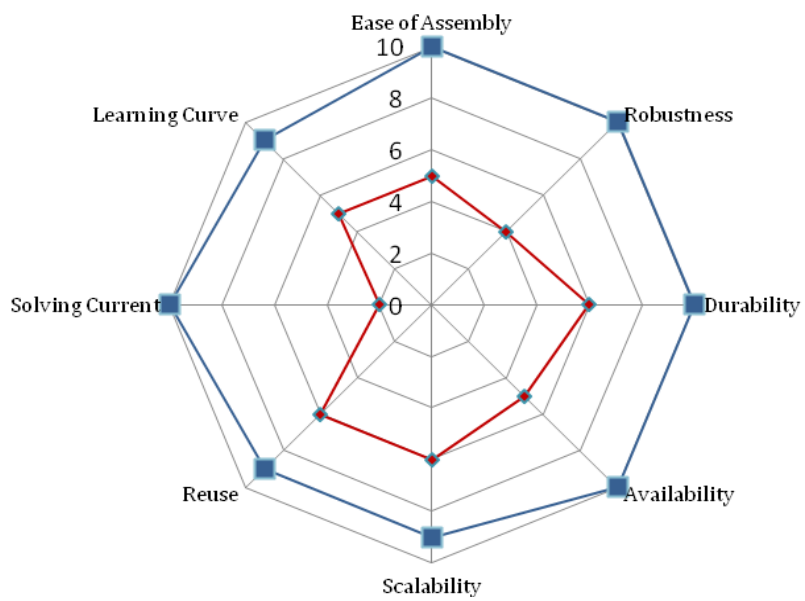

$\rightarrow$ WaterBoxx

- -Used Tires

Fig. 3: Quality profiles of original design (in red) and proposed alternative design (in blue)

- The southern area of Kuwait (UMM Al-Heyman Residential Area): to build a green belt around the area to reduce air contaminants.

The research team will be utilizing the latest in environmental techniques and computer based simulation to produce a solid case study of the success factor of implementing such project in Kuwait. Candidate areas of implementation will be:
- The green wall of Kuwait: A national project with the help of oil sector is underway to try to plant three rows of trees all around the Kuwaiti land borders [6].

- Greenification of northern area (Mutla) to stabilize the sand and reduce the dust pollution by reducing the frequency of dust storms as Kuwait has over $80 \%$ of 
the time predominant wind from North and northwest commonly known as "Al-Shamal"

- Farms: Using a case study in multiple farms in Kuwait to practically demonstrate that the proposed methodology will work as fine as proposed [10].

The proposed methodology would be tested on a variety of farms for its proper evaluation. To address this point, the proponents propose to have 4 candidate locations. In each location, tentatively four farms of around 5000 square yards each would be selected, this is explained in Table III.

TABLE III

SET OF CANDIDATE LOCATIONS FOR TESTING PROPOSED METHODOLOGY

\begin{tabular}{|lcc|}
\hline Locations & \# of Farms & Area of each Farm \\
\hline Location \# 1 & 4 & 5000 Square yard \\
\hline Location \# 2 & 4 & 5000 Square yard \\
\hline Location \# 3 & 4 & 5000 Square yard \\
\hline Location \# 4 & 4 & 5000 Square yard \\
\hline
\end{tabular}

\section{CONCLUDING REMARKS}

Based on the success of this pilot case, a plan will be laid to more comprehensive national project to utilize all use care resources in fighting desertification and water rationing.

In this paper, due to lack of space we choose not the achievements of the research thus far including the following:

- Budget, equipment \& manpower

- Coordination with government agencies

- Filed tests and observations

- Prototype kit building \& testing

- Awards, patents and presentations

\section{ACKNOWLEDGMENT}

This research is funded by Kuwait Foundation for Advancement of Science, project number 2013150101. Kuwait University Research Sector support is also acknowledged for running the same project.

\section{REFERENCES}

[1] eFunda, Inc. "Rapid Prototyping: An Overview". Efunda.com. Retrieved 2013-06-14.

[2] Greg Gibbons, Interview about Additive Manufacturing, WMG, University of Warwick", Warwick University, KnowledgeCentre. Accessed 18 October 2013.

[3] NSF JTEC/WTEC Panel Report-RPA http://www.wtec.org/pdf/rp_vi.pdf.

[4] Medical_applications_of_rapid_prototyping_a_new_horizon.pdf

[5] Geist, Helmut. 2005, The Causes And Progression Of Desertification, Ashgate Publishing.

[6] https://en.wikipedia.org/wiki/Desertification.

[7] SAVE International@: http://www.value-eng.org/

[8] Blackman, A., and Bannister G. 1998. Community Pressure and Clean Technology in the informal Sector; An Economic Analysis of the adoption of propane by Traditional Mexican Brikmaker, J. of Environmental Economics \& management 36, 1 1-21

[9] Böer, B. 1998. Anthropogenic factors and their potential impacts on the sustainable development of Abu-Dhabi; terrestrial biological resources, Int. J. of Sustainable Development and World Ecology 5 125-135.

http://dx.doi.org/10.1080/13504509809469976
[10] Bowker, G.E., Baldauf, R., Isakov, V., Khlystov, A. and Petersen, W. 2007. The effect of roadside structures on the transport and dispersion of ultrafine particles from highways, Atmospheric Environment 41,37 8128-8139.

[11] Darwish, M.A., Al-Awadhi, F.M., Darwish, A.M. 2008. Energy and water in Kuwait Part I. A sustainability view point. Desalination 225: 341-355

http://dx.doi.org/10.1016/j.desal.2007.06.018

[12] El-Kharraz, J., El-Sadek, A., Ghaffour, N., Mino, E. 2012. Water scarcity and drought in WANA countries. Procedia Engineering 33: 14 $-29$

http://dx.doi.org/10.1016/j.proeng.2012.01.1172

[13] Skidmore, E.L. 1986. Wind erosion climatic erosivity, Climate Change 9 209-218.

http://dx.doi.org/10.1007/BF00140537

[14] Tetsuzo, O. 1999. Greenhouse effectiveness and greenification Basic Study of Environmental Assessment in term of energy recycle system of carbon dioxide, 26,216-220

[15] Wilfred H. Roudebush. An Environmental Value Engineering Application to Assess the Environmental Impact of Construction Waste, North Carolina Recycling Association 8th Annual NCRA Conference and 3rd Annual Southeastern Green building Conference March 2-4, 1998, Greensboro, NC, USA.

[16] Martyn R. Philips. Toward Sustainability \& Conesus Through Value Management, International Conference of Hong Kong Institute of Value Management, 1999, Hong Kong.

[17] Martyn R. Philips. Environmental Strategic Choice Through Value Management, Value World Journal, SAVE International, Spring 2000.

[18] Olson D, Delen D. Advanced Data Mining Techniques, Springer, $1^{\text {st }}$ edition, 2008.

[19] Bacchelli A, Lanza M, Robbes R. Linking e-mails and source code artifacts, Proceedings of the $32^{\text {nd }}$ ACM/IEEE International Conference on Software Engineering, Cape Town, South Africa, 2010, 1, pp. 375384.

http://dx.doi.org/10.1145/1806799.1806855

[20] Diego Schiavon. Report: the Groasis waterboxx, The Management Board of the La Primavera Agricultural Cooperative, ISTC 01 Technical Communication Techniques, 2012.

[21] Gewin, V. 2014, "Next-gen greenhouses support desert agriculture", Frontiers in Ecology and the Environment, vol. 12, no. 10, pp. 542-542.

[22] Kruschwitz, N. 2015, "To Conserve Water for Agriculture, a Solution from the Desert", MIT Sloan Management Review, vol. 56, no. 2, pp. 0.

[23] Zeng, R.S., Luo, S.M. \& Mallik, A.U. 2008, Allelopathy in Sustainable Agriculture and Forestry, Springer-Verlag, New York, NY. http://dx.doi.org/10.1007/978-0-387-77337-7

[24] Juo, A.S.R. \& Franzluebbers, K. 2003, Tropical soils: properties and management for sustainable agriculture, Oxford University Press, GB.

[25] Soil Biological Fertility: A Key to Sustainable Land Use in Agriculture, 2004, Springer Netherlands.

[26] Abdelly, C., Ashraf, M., Grignon, C. \& Öztürk, M. 2008, Biosaline Agriculture and High Salinity Tolerance, Birkhäuser, DE. http://dx.doi.org/10.1007/978-3-7643-8554-5

[27] Oron, G., Gillerman, L., Bick, A., Manor, Y., Buriakovsky, N. \& Hagin, J. 2008, "Membrane technology for sustainable treated wastewater reuse: Agricultural, environmental and hydrological considerations", Water Science and Technology, vol. 57, no. 9, pp. 1383-1388. http://dx.doi.org/10.2166/wst.2008.243

[28] Barnes, C. \& Flynn, R. 1998, Water conservation in New Mexico agriculture, .

[29] Venugopalan, V. 1997, Water conservation methods, .

[30] Unger, P. \& Howell, T. 1999, Agricultural water conservation - A global perspective, .

[31] Piccinni, G., Supercinski, D., Leskovar, D., Harris, B. \& Jones, C. 2006, Rio Grande Basin water conservation project, .

[32] Lauren M. Porensky, Jay Davison, Elizabeth A. Leger, W. Wally Miller, Erin M. Goergen, Erin K. Espeland, Erin M. Carroll-Moore, Grasses for biofuels: A low water-use alternative for cold desert agriculture?, Biomass and Bioenergy, Volume 66, July 2014, Pages. 